\title{
Species composition, seasonal occurrence, habitat preference and altitudinal distribution of malaria and other disease vectors in eastern Nepal
}

Meghnath Dhimal ${ }^{1,2,3,4^{*}}$, Bodo Ahrens ${ }^{2,3}$ and Ulrich Kuch ${ }^{4}$

\begin{abstract}
Background: It is increasingly recognized that climate change can alter the geographical distribution of vector-borne diseases (VBDs) with shifts of disease vectors to higher altitudes and latitudes. In particular, an increasing risk of malaria and dengue fever epidemics in tropical highlands and temperate regions has been predicted in different climate change scenarios. The aim of this paper is to expand the current knowledge on the seasonal occurrence and altitudinal distribution of malaria and other disease vectors in eastern Nepal.

Methods: Adult mosquitoes resting indoors and outdoors were collected using CDC light trap and aspirators with the support of flash light. Mosquito larvae were collected using locally constructed dippers. We assessed the local residents' perceptions of the distribution and occurrence of mosquitoes using key informant interview techniques. Generalized linear models were fitted to assess the effect of season, resting site and topography on the abundance of malaria vectors.

Results: The known malaria vectors in Nepal, Anopheles fluviatilis, Anopheles annularis and Anopheles maculatus complex members were recorded from 70 to 1,820 m above sea level (asl). The vectors of chikungunya and dengue virus, Aedes aegypti and Aedes albopictus, the vector of lymphatic filariasis, Culex quinquefasciatus, and that of Japanese encephalitis, Culex tritaeniorhynchus, were found from 70 to 2,000 m asl in eastern Nepal. Larvae of Anopheles, Culex and Aedes species were recorded up to 2,310 m asl. Only season had a significant effect on the abundance of An. fluviatilis, season and resting site on the abundance of An. maculatus complex members, and season, resting site and topography on the abundance of An. annularis. The perceptions of people on mosquito occurrence are consistent with entomological findings.
\end{abstract}

Conclusions: This study provides the first vertical distribution records of vector mosquitoes in eastern Nepal and suggests that the vectors of malaria and other diseases have already established populations in the highlands due to climatic and other environmental changes. As VBD control programmes have not been focused on the highlands of Nepal, these findings call for actions to start monitoring, surveillance and research on VBDs in these previously disease-free, densely populated and economically important regions.

Keywords: Aedes, Anopheles, Culex, Climate change, Dengue, Elimination, Japanese encephalitis, Lymphatic filariasis, Mosquito-borne diseases

\footnotetext{
* Correspondence: meghdhimal@gmail.com

${ }^{1}$ Nepal Health Research Council (NHRC), Ministry of Health and Population

Complex, Ramshah Path, Kathmandu, Nepal

${ }^{2}$ Biodiversity and Climate Research Centre (BiK-F), Senckenberg Gesellschaft

für Naturforschung, Frankfurt am, Germany

Full list of author information is available at the end of the article
} 


\section{Background}

Malaria, transmitted by the bite of infected Anopheles mosquitoes, also known as malaria vectors, is the oldest reported tropical disease in Nepal. The first efforts to survey the mosquitoes and identify the vectors of malaria in Nepal were initiated in 1952 [1]. So far, 44 species of Anopheles mosquitoes have been identified in Nepal based on morphological characteristics but only seven have been reported as malaria vectors of primary importance [2,3]. These include: Anopheles minimus, Anopheles fluviatilis, Anopheles annularis, Anopheles maculatus, Anopheles dravidicus, Anopheles pseudowillmori, and Anopheles willmori [3]. The last four species are commonly reported as 'Anopheles maculatus complex members' in Nepal. It has been reported that deforestation and effective control using DDT practically eliminated An. minimus in Nepal during the 1960s [4], and An. fluviatilis is now the primary malaria vector in Nepal, An. annularis the secondary malaria vector and the $A n$. maculatus complex members are seasonal malaria vectors in the mountain region of Nepal [2-6]. However, in absence of molecular tools at that time, the reported selective elimination of An. minimus from Nepal might have reflected taxonomic uncertainty with respect to morphologically cryptic mosquito species rather than a real elimination from the country $[7,8]$. Other Anopheles species from the group of 44 have been incriminated elsewhere in Asia [9-11] and may play a role in malaria transmission under changing environments and climate in Nepal [12].

Entomological surveys of malaria vectors are very important for controlling vector populations and diseases in the community. However, little attention has been given to entomological surveillance and vector control in Nepal $[4,6,13,14]$. In addition, a government effort to control malaria is further threatened by insecticide and drug resistance developing in vectors and malaria parasites, a changing environment and climate, and an increasing mobility of people travelling to and from malaria endemic areas within the country and across international borders $[4,13,15]$.

The medical entomology surveys of the past showed that the distribution of malaria vectors and their malaria transmission capacity were confined to altitudes below 1,200 $\mathrm{m}$ above sea level (asl) in Nepal. Accordingly, the national malaria control programme only covers the area below 1,200 $\mathrm{m}$ [6,13,16-18]. The continuous effort of government and external development partners to control malaria in high endemic areas, with massive intervention programmes such as the distribution of insecticide treated bed nets and indoor residual spraying, has significantly reduced the total number of confirmed malaria cases over the years in Nepal [8]. Despite this achievement, malaria cases which had once been confined to the lowlands and forest areas are now already reported from highland areas of Nepal above 2,000 m [19]. However, medical entomology evidence is lacking to explain whether malaria vectors causing local transmission are established in high altitude habitats of Nepal or not.

Recent evidence suggests that the warming rate in higher altitudes and latitudes is faster than in the lowlands [20-22]. This is also supported by the analysis of climate data in Nepal [23-28]. The changing climate and other factors can thus create a conducive environment for the survival, development and breeding of mosquitoes in new areas. Many recent studies have predicted an impact of climate change on the geographical distribution of disease vectors [29-31] and an increasing epidemic potential of vector-borne diseases (VBDs; mainly malaria and dengue fever) in temperate regions and tropical highlands [32-35]. The altitudinal transect survey carried out for the preparation of the National Adaptation Programme of Actions to climate change (NAPA) in Nepal reports that mosquito nuisance has increased in the highlands over the last decade [36] and identifies VBDs as one of the major adaptation projects in the public health theme. Stimulated by these assumptions and events, we aimed to expand the current knowledge on the seasonal occurrence and altitudinal distribution of malaria vectors in eastern Nepal. We also aimed to document the seasonal occurrence and altitudinal distribution of the vectors of other major VBDs (dengue fever, lymphatic filariasis and Japanese encephalitis) if captured during the collection of Anopheles mosquitoes. However, we performed detailed statistical analyses of malaria vectors only because some important potential habitats of other VBD vectors such as discarded tires and other containers were not inspected, and many adults and larvae of Culex quinquefasciatus mosquitoes were not collected due to their large abundance in some areas. Therefore, the abundance data of these other disease vectors is not representative for inferential statistical analysis. Nevertheless, this study provides the first evidence of the altitudinal distribution of the vectors of malaria and other major mosquitoborne diseases in eastern Nepal.

\section{Methods}

Description of the study area and sampling techniques Surveys were carried out from September to October 2012 and April to May 2013 at fixed locations of three districts (Morang, Dhankuta and Terhathum) of eastern Nepal. The altitudes of the study sites vary from $70 \mathrm{~m}$ to $2,500 \mathrm{~m}$ asl. The study area was defined along an altitudinal transect and divided into lowland $(<1,500 \mathrm{~m}$ asl) and highland parts $(\geq 1,500 \mathrm{~m}$ asl $)$ in terms of topography. In each locality, the collection spots faced different directions, and random collections were performed from each and every possible habitat. The map of study area is shown in Figure 1. 


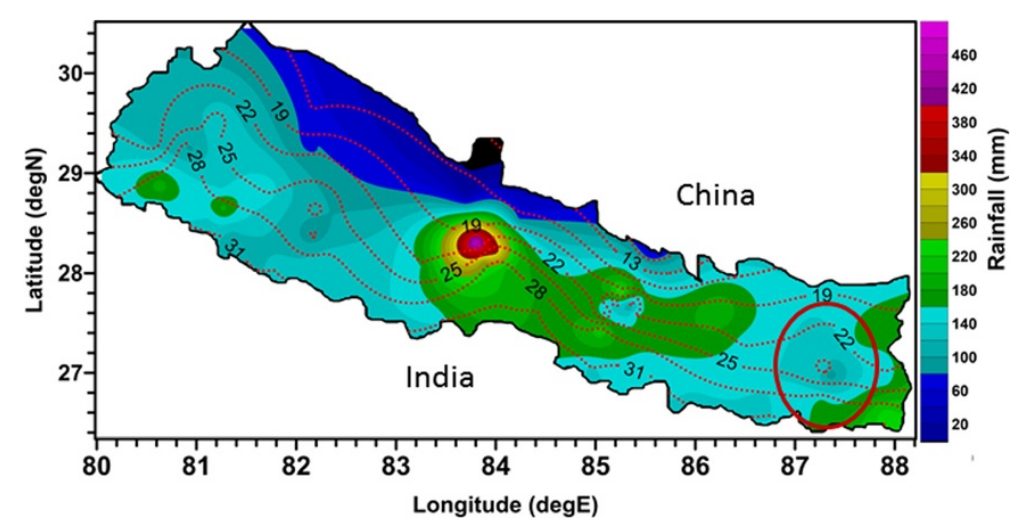

Figure 1 Map of Nepal showing the study area (marked by red circle). The map is a rough sketch and not to scale. Data for isohyets and isothermal contours was provided by the Department of Hydrology and Meteorology, Government of Nepal.

The average annual temperature of the study area ranges from about $31^{\circ} \mathrm{C}$ in the lowlands to about $22^{\circ} \mathrm{C}$ in the highlands. Similarly, the mean annual rainfall decreases from about $180 \mathrm{~mm}$ in the lowlands to less than $100 \mathrm{~mm}$ in the highlands. Both temperature and rainfall are favourable for the survival of Anopheles species, but it will be limited at least by the winter temperature which falls below $5^{\circ} \mathrm{C}$. The altitude of eastern Nepal ranges from about $60 \mathrm{~m}$ to over $8,000 \mathrm{~m}$ asl. The highest peak mountains of the world above 8,000 m, Mt. Everest, Makalu and Kanchenjunga also lie in eastern Nepal where the Kanchenjunga and Makalu Himalayas stand just above our study area.

\section{Sampling of mosquitoes and identification}

The eastern development region (equivalent to province) was purposively selected for this study from among the five development regions of Nepal. Subsequently the districts Morang, Dhankuta and Terathum were chosen for our study because they meet the criteria of covering high, moderate and low malaria transmission risk areas as well as ample altitudinal variation ranging from about $70 \mathrm{~m}$ to above $2,500 \mathrm{~m}$. In consultation with District Public Health Offices and government medical entomologists, and by analyzing routine health surveillance data of malaria, 19 village development committees (VDC) were chosen for the entomological surveys in these districts. From each VDC at least 20 houses, natural outdoor shelters in their vicinity and potential breeding places were selected in each season (pre-monsoon and post-monsoon).

The entomological surveys were performed for one month (mid-September to mid-October) in 2012 and (mid-April to mid-May) in 2013. Adult mosquito sampling and the collection of immature stages was carried out as per WHO guidelines [37]. Mosquitoes resting indoors and outdoors were collected using flashlights and aspirators in the early morning (5:00-8:00 am). The rationale for making collections as early in the morning as possible was to avoid disturbance to mosquitoes by smoke from kitchens and by sun light. For collecting resting mosquitoes outdoors, natural shelters such as tree holes, stone cavities, erosion furrows, empty animal sheds and piles of firewood were inspected. Adult mosquitoes were also collected using a CDC light trap in human houses and animal shelters. The trap was set up in locations that were far away from competing light sources and hung up about $1.5 \mathrm{~m}$ above ground from dusk to dawn during one night per household or cattle shed. The light trap was kept turned on overnight. On the next morning the catch bag was removed and mosquitoes were immobilized with chloroform (ethanol stabilized; RFCL Limited, New Delhi) and identified using taxonomic keys and catalogues [3,38,39]. Small rain pools, seepage, streams, tree holes, water tanks ponds, rock pool, stone cave and artificial container such as discarded tires were surveyed for the presence of larvae, and collection were made by applying a standard sampling procedure described elsewhere $[37,40]$. Depending on the size of breeding habitat and the availability of larvae, three to ten samples were taken from each larval habitat. In streams, dipping was carried out at the edges and stream beds for a distance $300 \mathrm{~m}$ to $2,310 \mathrm{~m}$ depending on presence of larvae and access of stream water for sampling.

The identified mosquitoes were immediately transferred to cryovials and deep frozen in an MVE Doble 11 Dry Shipper using nitrogen vapor. Due to time and logistic constraints, mosquitoes were in some cases directly transferred to the dry shipper after identifying specimens up to genus level. Mosquito larvae were identified up to genus level using taxonomic and pictorial keys [3]. Then, the larvae were deep frozen in liquid nitrogen for species level identification using molecular genetic techniques (studies in progress). 


\section{People's perception data}

As no previous altitudinal distribution data of mosquitoes was available for eastern Nepal, we assessed the perception of local people in the study areas about the distribution and occurrence of mosquitoes. For this we performed key informant interviews with those community leaders, social workers, teachers and health workers who had lived there for at least 30 years. The information collected mainly reflected the perception of people about the appearance of mosquitoes in terms of chronological order, associated causes for this, and perceived health risks.

\section{Environmental data}

We collected the geographical coordinates, altitudes and environmental data of the study sites such as the number of animals kept in sheds, the number of persons who slept in the house in the night preceding the survey, etc. Mosquito collection resting sites were broadly categorized into human shelter (HS), animal shelter (AS), mixed shelter of animals and humans (MS) and natural outdoor shelter (NOS). The types of larval habitats and their characteristics such as description of habitat (i.e., temporary or permanent), water flow (i.e., stagnant or flowing), water condition (i.e., turbid, clean, polluted or turbid as well as polluted), water light (i.e., sunny or shaded) and water vegetation (i.e., with or without vegetation) were noted.

\section{Data analysis}

The data were entered in Microsoft Excel 2010 spreadsheets and analyzed using $\mathrm{R}$ software [41]. The GPS coordinates of mosquito sampling points and malaria vector positive sites were projected onto maps with ArcGis software (ArcGis10, ESRI). The abundance data of mosquitoes were not normally distributed and showed a clumped distribution (variance $>$ mean). Therefore, generalized linear models (GLM) were fitted assuming a negative binomial distribution and a log link function using the "Mass" package in R [42]. We fitted separate models for each species adult abundance of malaria vectors using season, topography (i.e., either lowland or highland) and resting sites of mosquitoes (i.e., animal shelter, human shelter, mixed human and animal shelter, natural outdoor shelters) as explanatory variables. Our models can be summarized as

Adult abundance $\sim$ Season + Resting site + Topography

We assessed the multicollinearity of the explanatory variables for each model using variance inflation factors (VIFs) which were less than 2.0. We used Akaike's information criterion (AIC) to select the final model. Information on people's perception of mosquitoes and mosquito-borne diseases was collected from eight qualitative interviews and manually summarized.

\section{Ethical approval}

The conduct of this study was approved by the Ethical Review Board of the Nepal Health Research Council (NHRC), Government of Nepal. Oral informed consent was taken from the head of each household before starting the collection of mosquitoes either in houses or animal shelters. In cases where the household head disagreed, the house was dropped from the collection plan and the immediate next one was chosen for study. Written informed consent was taken from key informant interviewees.

\section{Results}

\section{Mosquito species composition}

A total of 2,538 adult mosquitoes belonging to the four genera Aedes (10\%), Anopheles (55\%), Armigeres (6\%) and Culex (29\%) were collected in both seasons (Table 1). Among the Aedes specimens $(\mathrm{n}=245)$, the known dengue virus vectors in Nepal, Aedes aegypti and Aedes albopictus, constituted $3 \%$ and $4 \%$, respectively. The principal vector of lymphatic filariasis, C. quinquefasciatus, and the Japanese encephalitis virus vector Culex tritaeniorhynchus accounted for $12 \%$ and $31 \%$ of the total collected Culex mosquitoes $(\mathrm{n}=742)$. Similarly, the known malaria vectors in Nepal, An. annularis, An. fluviatilis and An. maculatus complex members, represented $16 \%, 9 \%$ and $10 \%$ of the total collected Anopheles mosquitoes ( $\mathrm{n}=1396)$. Hence, about 35\% of the total Anopheles mosquitoes belonged to species that are known malaria vectors. The relative abundance of adult mosquitoes and their resting sites are presented in Table 1. Among the total Anopheles mosquitoes collected, 15\% could not be identified up to species level under field conditions due to logistic and time constraints; these were directly preserved for molecular studies. About 23\% of the collected Anopheles mosquitoes were assigned to Anopheles spp. other than the malaria vectors identified here based on morphological characters. Malaria vectors were found at all sampled seasons, topography and resting site (i.e., animal, human, mixed and natural outdoor shelters).

Similarly, a total of 188 larvae of mosquitoes belonging to the three genera Aedes (49.5\%), Anopheles (33\%) and Culex (17.5\%) were collected in both seasons (Table 1). We did not collect larvae of genus Armigeres because of their large abundance in most of the sampling habitats. The seasonal abundance and larval habitats of mosquitoes is presented in Table 2.

\section{Seasonal occurrence of vector mosquitoes}

All of the known malaria vectors in Nepal, An. annularis, An. fluviatilis and An. maculatus complex members, were recorded in both sampling seasons. The relative abundance of malaria vectors by season is shown in Figure 2. The dengue virus vector $A$. aegypti was only recorded in the post-monsoon season but other vectors (A. albopictus, 
Table 1 The seasonal abundance of adult mosquitoes and their resting sites

\begin{tabular}{|c|c|c|c|c|c|c|c|}
\hline \multirow[t]{2}{*}{ Mosquitoes species } & \multicolumn{2}{|l|}{ Pre-monsoon } & \multicolumn{2}{|l|}{ Post-monsoon } & \multicolumn{2}{|l|}{ Both season } & \multirow[t]{2}{*}{ Resting sites } \\
\hline & $\begin{array}{l}\text { Total } \\
\text { collected (N) }\end{array}$ & $\begin{array}{l}\text { Relative } \\
\text { abundance (\%) }\end{array}$ & $\begin{array}{l}\text { Total } \\
\text { collected (N) }\end{array}$ & $\begin{array}{l}\text { Relative } \\
\text { abundance (\%) }\end{array}$ & $\begin{array}{l}\text { Total } \\
\text { collected (N) }\end{array}$ & $\begin{array}{l}\text { Relative } \\
\text { abundance (\%) }\end{array}$ & \\
\hline \multicolumn{8}{|l|}{ Aedes $(n=245)$} \\
\hline Aedes aegypti & 0 & 0 & 8 & 0.4 & 8 & 0.3 & AS,NOS \\
\hline Aedes albopictus & 8 & 1.2 & 3 & 0.2 & 11 & 0.4 & $\mathrm{HS}, \mathrm{HS}$ \\
\hline Aedes spp. & 13 & 1.9 & 213 & 0.0 & 226 & 8.9 & $\mathrm{AS}, \mathrm{HS}, \mathrm{NOS}$ \\
\hline \multicolumn{8}{|l|}{ Culex $(n=742)$} \\
\hline Culex quenquifasciatus & 87 & 12.7 & 4 & 0.2 & 91 & 3.6 & HS,AS \\
\hline Culex tritaeniorhynchus & 11 & 1.6 & 217 & 11.7 & 228 & 9.0 & $\mathrm{AS}, \mathrm{HS}$ \\
\hline Unidentified Culex & 54 & 7.9 & 369 & 19.9 & 423 & 16.7 & $\mathrm{AS}, \mathrm{HS}, \mathrm{NOS}$ \\
\hline \multicolumn{8}{|l|}{ Anopheles $(n=1396)$} \\
\hline Anopheles aconitus & 1 & 0.1 & 1 & 0.1 & 2 & 0.1 & AS \\
\hline Anopheles nivipes & 3 & 0.4 & 2 & 0.1 & 5 & 0.2 & AS \\
\hline Anopheles tessellatus & 10 & 1.5 & 1 & 0.1 & 11 & 0.4 & AS \\
\hline Anopheles nigerrimus & 8 & 1.2 & 6 & 0.0 & 14 & 0.6 & $\mathrm{AS}, \mathrm{HS}$ \\
\hline Anopheles barbirostris & 10 & 1.5 & 9 & 0.5 & 19 & 0.7 & $\mathrm{AS}, \mathrm{HS}$ \\
\hline Anopheles splendidus & 13 & 1.9 & 16 & 0.9 & 29 & 1.1 & $\mathrm{AS}, \mathrm{HS}$ \\
\hline Anopheles sinensis & 23 & 3.4 & 14 & 0.8 & 37 & 1.5 & $\mathrm{AS}, \mathrm{HS}, \mathrm{NOS}$ \\
\hline Anopheles culicifacies & 25 & 3.6 & 18 & 1.0 & 43 & 1.7 & AS,HS,MS,NOS \\
\hline Anopheles pallidus & 32 & 4.7 & 66 & 0.0 & 98 & 3.9 & AS \\
\hline Anopheles vagus & 86 & 12.6 & 22 & 0.0 & 108 & 4.3 & $\mathrm{AS}, \mathrm{HS}, \mathrm{MS}$ \\
\hline Anopheles fluviatilis & 5 & 0.7 & 116 & 6.3 & 121 & 4.8 & $\mathrm{AS}, \mathrm{HS}, \mathrm{NOS}$ \\
\hline Anopheles maculatus complex & 114 & 16.6 & 25 & 1.3 & 139 & 5.5 & $\mathrm{AS}, \mathrm{HS}, \mathrm{NOS}$ \\
\hline Anopheles annularis & 27 & 3.9 & 201 & 10.8 & 228 & 9.0 & $\mathrm{AS}, \mathrm{HS}, \mathrm{MS}$ \\
\hline Anopheles spp. & 74 & 10.8 & 258 & 13.9 & 332 & 13.1 & AS \\
\hline $\begin{array}{l}\text { Unidentified } \\
\text { Anopheles }\end{array}$ & 0 & 0.0 & 210 & 11.3 & 210 & 8.3 & $\mathrm{HS}$ \\
\hline \multicolumn{8}{|l|}{ Armigeres $(n=155)$} \\
\hline Armigeres spp. & 81 & 11.8 & 74 & 4.0 & 155 & 6.1 & $\mathrm{AS}, \mathrm{HS}, \mathrm{NOS}$ \\
\hline Total & 685 & 100 & 1853 & 100 & 2538 & 100 & \\
\hline
\end{tabular}

$\mathrm{AS}=$ Animal shelter, $\mathrm{HS}=$ Human shelter, MS = Mixed shelter of human and animal, NOS = Natural Outdoor Shelter.

C. quinquefasciatus and C. tritaeniorhynchus) were found in both seasons. Similarly, larva stage of three genera Aedes, Anopheles and Culex were found in both seasons (Table 2).

\section{Altitudinal distribution of vector mosquitoes}

All three known malaria vector species were found throughout the studied altitude range up to $1,820 \mathrm{~m}$ asl (Figure 3). Similarly, other disease vectors A. aegypti, $A$. albopictus, C. quinquefasciatus and C. tritaeniorhynchus were also collected throughout the studied transect ranging from 70 to $2,000 \mathrm{~m}$ asl. We also collected Anopheles, Culex and Aedes larvae up to 2,310 $\mathrm{m}$ in our study area; their DNA-based species identification is in progress.

\section{Effect of season, topography and resting site on vector} abundance

The effects of season, topography and resting site on the abundance of adult malaria vectors is summarized in Table 3. Only season had a significant effect on the mean abundance of $A n$. fluviatilis. Compared to the postmonsoon (rainy) season, the abundance of An. fluviatilis was only $6 \%(95 \% \mathrm{CI}=0.01-0.31, \mathrm{P}<0.01)$ in the premonsoon (dry). The abundance of An. fluviatilis was 48 times higher in lowland $(<1,500 \mathrm{~m}$ asl) compared to highland habitats ( $>1,500 \mathrm{~m}$ asl) $(95 \% \mathrm{CI}=6.06-380.97$, $\mathrm{P}=0.06)$ although this difference was not statistically significant. Season, topography and resting site had significant effects on the mean abundance of An. annularis. The mean abundance of $A n$. annularis was only $15 \%$ in the 
Table $\mathbf{2}$ The seasonal abundance of mosquitoes larvae and their habitats

\begin{tabular}{|c|c|c|c|c|}
\hline \multirow[t]{2}{*}{ Characteristics } & \multicolumn{3}{|c|}{ Larvae of collected mosquitoes genera } & \multirow[b]{2}{*}{ Total } \\
\hline & Aedes & Anopheles & Culex & \\
\hline \multicolumn{5}{|l|}{ Pre-monsoon } \\
\hline Total collected & 61 & 51 & 15 & 127 \\
\hline Breeding habitats & $\begin{array}{l}\text { Stream, tree hole, water tanks, } \\
\text { discarded tyre }\end{array}$ & $\begin{array}{l}\text { Stream, seepage, water tanks, } \\
\text { paddy fields }\end{array}$ & $\begin{array}{l}\text { Stream, seepage, } \\
\text { water tanks }\end{array}$ & \\
\hline Description of breeding habitat & $\mathrm{T} / \mathrm{P}$ & $\mathrm{T} / \mathrm{P}$ & $\mathrm{T} / \mathrm{P}$ & \\
\hline Water condition & $\mathrm{T} / \mathrm{C}$ & $\mathrm{T} / \mathrm{C}$ & $\mathrm{T} / \mathrm{C} / \mathrm{P}$ & \\
\hline Water flow & $S / F$ & $S / F$ & $S / F$ & \\
\hline Water light & $\mathrm{Su} / \mathrm{Sh}$ & $\mathrm{Su} / \mathrm{Sh}$ & $\mathrm{Su} / \mathrm{Sh}$ & \\
\hline Water vegetation & Both with/without & Both with/without & Both with/without & \\
\hline \multicolumn{5}{|l|}{ Post-monsoon } \\
\hline Total collected & 32 & 11 & 18 & 61 \\
\hline Breeding habitats & $\begin{array}{l}\text { Stream, tree hole, water tanks, } \\
\text { discarded tyre }\end{array}$ & Stream, seepage, tree holes & $\begin{array}{l}\text { Plastic drum, seepage, } \\
\text { water tanks }\end{array}$ & \\
\hline Description of breeding habitat & $\mathrm{T} / \mathrm{P}$ & $\mathrm{T} / \mathrm{P}$ & $\mathrm{T}$ & \\
\hline Water condition & C & C & $\mathrm{T} / \mathrm{C} / \mathrm{P}$ & \\
\hline Water flow & $S$ & $S / F$ & $\mathrm{~S}$ & \\
\hline Water light & Su & $\mathrm{Su} / \mathrm{Sh}$ & Sh & \\
\hline Water vegetation & Both with/without & Both with/without & Both with/without & \\
\hline Total collected larvae in both seasons & 93 & 62 & 33 & 188 \\
\hline Relative abundance (\%) & 49.5 & 33.0 & 17.5 & 100 \\
\hline
\end{tabular}

$\mathrm{S} / \mathrm{F}=$ Stagnant $/$ Flowing $\mathrm{Su} / \mathrm{Sh}=$ Sunny $/$ Shaded $\mathrm{C}=\mathrm{Clear} \mathrm{S}=$ Stagnant.

pre-monsoon compared to the post-monsoon season $(95 \%$ $\mathrm{CI}=0.04-0.53, \mathrm{P}<0.01)$, only $23 \%$ in human shelters $(95 \%$ $\mathrm{CI}=0.06-0.82, \mathrm{P}<0.05)$ compared to animal shelters, and 4.25 times higher in lowland compared to highland habitats (95\% CI $=1.09-16.62, \mathrm{P}<0.05)$. Similarly, only season and resting site had significant effects on the mean abundance of $A n$. maculatus complex members. The mean abundance of An. maculatus complex members was 3.50 times higher in pre-monsoon compared to post-monsoon (95\%

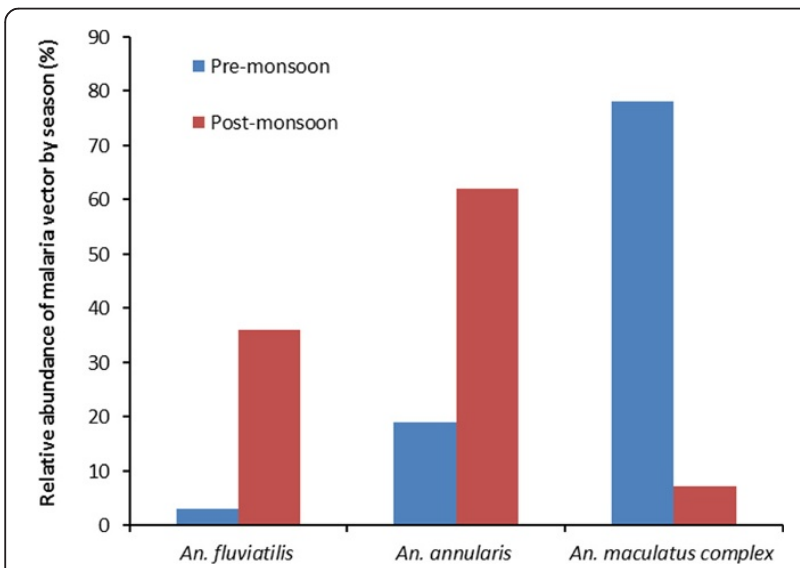

Figure 2 Relative abundance of malaria vectors by season in eastern Nepal.
$\mathrm{CI}=1.10-1.15, \mathrm{P}<0.05)$ and only $25 \%$ in human compared to animal shelters $(95 \% \mathrm{CI}=0.08-0.83, \mathrm{P}<0.05)$.

\section{People's perception of mosquito occurrence and distribution}

The local people of lowland areas did not perceive any change in the occurrence and distribution of mosquitoes in their communities. However, they reported that mosquito biting problems at night now had prolonged seasons including in winter whereas in the past this was limited mainly to the pre-monsoon and monsoon seasons (AprilSeptember). They also reported that people increasingly used bed nets at night and that malaria incidence had declined compared to the past. In contrast, people of highland areas perceived that mosquito nuisance had started in their communities as recently as 5-10 years ago and increasingly became a problem as mosquito bites started immediately after winter and lasted until the end of autumn. All participants univocally responded that the use of bed-nets would prevent mosquitoes-borne diseases. Participants of highland areas believed that mosquitoes had been carried to the highlands by trucks and buses and the creation of breeding places following the installation of water supply pipes in communities, domestic water storage and growing mosquito populations favoured by warming temperatures in the last years. They also believed 


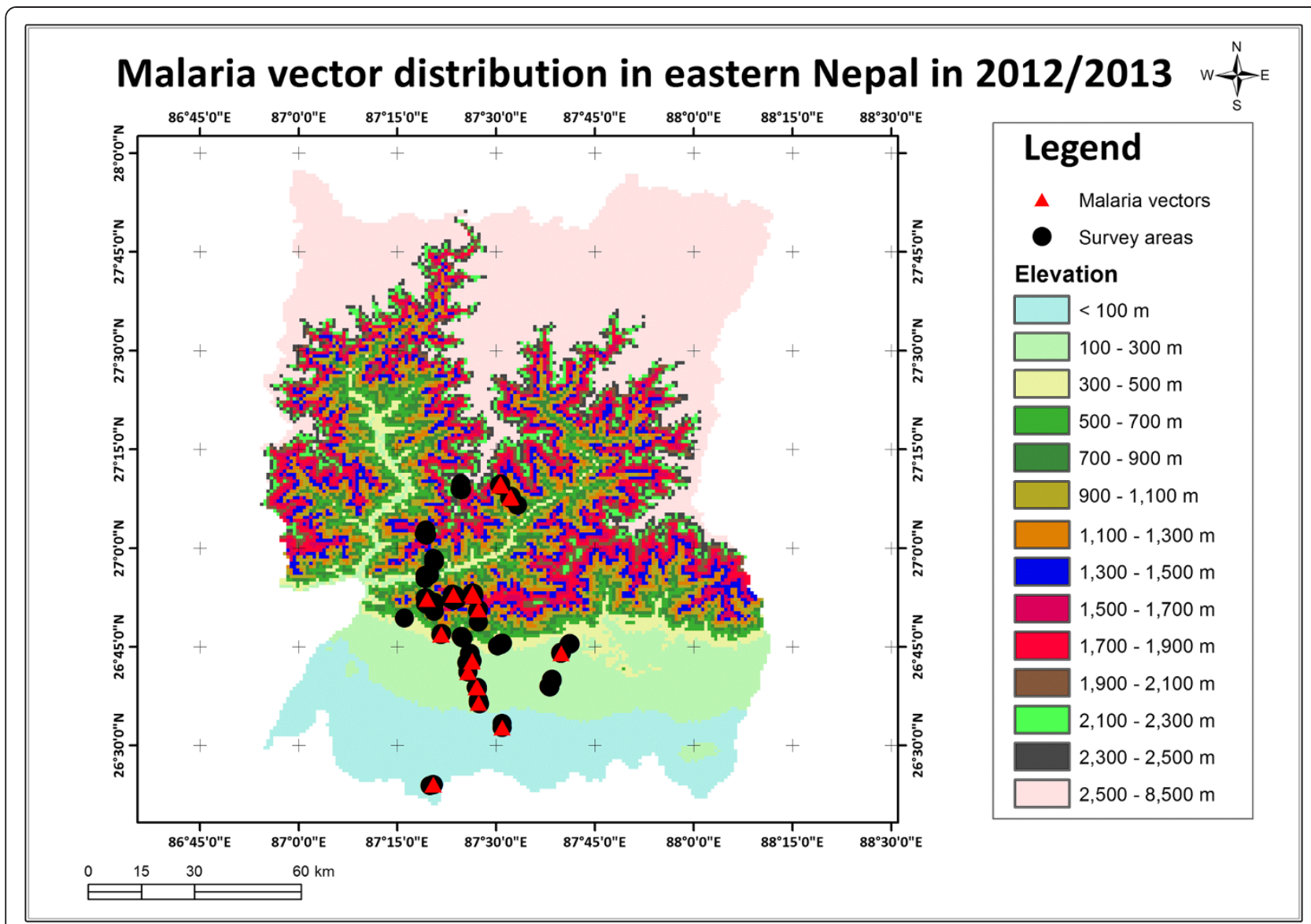

Figure 3 Altitudinal distribution of malaria vectors in eastern Nepal, 2012/2013. The altitudinal range surveyed extended from 70 to 2,500 m above sea level.

that the replacement of biomass solid fuel by electricity promoted mosquito populations in households because electric lights attract mosquitoes whereas smoke from kerosene lamps and biomass fuels repels mosquitoes. In summary, community people perceived mosquito occurrence and distribution in the highlands to be a recent event which coincided with development and environmental changes including pronounced temperature increases in the latest decade. For example, a 60-year-old community leader in Dandabazar, Dhankuta (1,900 m asl), summarized his experience as follows: "I have been living here for 40 years and a lot of development changes occurred over the years which are good as well as bad. For example, the development of residential areas and rural roads in the highlands has made our life easier, but at the same time mosquitoes which used to be found in the lowlands are now transported to the highlands and are established in our areas above 2,000 $\mathrm{m}$ altitude. This is primarily due to imported goods transported by buses and trucks from the lowlands and overnight stays of vehicles in the highlands. Unplanned urbanization as well as pig farming in densely populated settlements of the highlands have attracted and fostered larger mosquito populations. No matter if these mosquitoes cause diseases or not; every day we have to face mosquito bites, at least six months per year. No mosquito-borne diseases have ever been reported in our village but this may be due to the lack of diagnostic facilities in health posts and because seriously ill people are referred to the big hospitals in the lowlands. Most households in our village use bed nets at least during the six months from April to September. They prevent mosquito-borne diseases. I do not know about climate change but we have experienced a warming over the years and this has also produced larger mosquito populations in our areas".

\section{Discussion}

This study provided information on the distribution of malaria vectors in eastern Nepal. The distribution of malaria vectors up to $1,820 \mathrm{~m}$ and the presence of Anopheles spp. larvae at 2,310 $\mathrm{m}$ asl are new records for eastern Nepal. All three known malaria vectors in this country, i.e., An. fluviatilis, An. annularis and An. maculatus complex members, were found to be distributed throughout the 
Table 3 Effects of season, resting site and topography on the abundance of malaria vectors

\begin{tabular}{|c|c|c|c|}
\hline $\begin{array}{l}\text { Dependent } \\
\text { variables }\end{array}$ & Explanatory variables & Coefficients & $95 \% \mathrm{Cl}$ \\
\hline \multirow[t]{9}{*}{ An. fluviatilis } & (Intercept) & 0.04 & $(0.01-0.27)^{* * *}$ \\
\hline & Season: Post-monsoon & 1.00 & 1.00 \\
\hline & Pre-monsoon & 0.06 & $(0.01-0.31)^{* *}$ \\
\hline & Resting site: Animal shelter & & \\
\hline & Human shelter & 0.28 & $(0.06-1.28)$ \\
\hline & Mixed shelter & ND & ND \\
\hline & Natural outdoor shelter & ND & ND \\
\hline & Topography: Highland & 1.00 & 1.00 \\
\hline & Lowland & 48.04 & $(6.06-380.97)$ \\
\hline \multirow[t]{9}{*}{ An. annularis } & (Intercept) & 0.35 & $(0.09-1.38)$ \\
\hline & Season: Post-monsoon & 1.00 & 1.00 \\
\hline & Pre-monsoon & 0.15 & $(0.04-0.53)^{* *}$ \\
\hline & Resting site:: Animal shelter & 1.00 & 1.00 \\
\hline & Human shelter & 0.23 & $(0.06-0.82)^{*}$ \\
\hline & Mixed shelter & 0.94 & $(0-853.43)$ \\
\hline & Natural outdoor shelter & ND & ND \\
\hline & Topography: Highland & 1.00 & 1.00 \\
\hline & Lowland & 4.25 & $(1.09-16.62)^{*}$ \\
\hline \multirow{9}{*}{$\begin{array}{l}\text { An. maculatus } \\
\text { complex }\end{array}$} & (Intercept) & 0.08 & $(0.02-0.30)^{* * *}$ \\
\hline & Season: Post-monsoon & 1.00 & 1.00 \\
\hline & Pre-monsoon & 3.50 & $(1.10-1.15)^{*}$ \\
\hline & Resting site: Animal shelter & 1.00 & 1.00 \\
\hline & Human shelter & 0.25 & $(0.08-0.83)^{*}$ \\
\hline & Mixed shelter & ND & ND \\
\hline & Natural outdoor shelter & 0.23 & $(0.02-3.02)$ \\
\hline & Topography: Highland & 1.00 & 1.00 \\
\hline & Lowland & 2.64 & $(0.76-9.14)$ \\
\hline
\end{tabular}

Significant difference at $\mathrm{P}<0.05\left({ }^{*}\right)$, at $\mathrm{P}<0.01\left(^{* *}\right)$ and at $\mathrm{P}<0.001\left(^{* * *}\right)$ (Two-tailed).

ND means not determined.

studied altitudinal range up to $1,820 \mathrm{~m}$ asl. Beside malaria vectors, mosquito species known to transmit the viruses causing dengue fever (A. aegypti and A. albopictus) and Japanese encephalitis (C. tritaeniorhynchus) as well as Wuchereria bancrofti microfilariae, the causative agents of lymphatic filariasis (C. quinquefasciatus), were encountered throughout the sampled altitudinal range from 70 to $2,000 \mathrm{~m}$ asl and probably (larvae pending molecular confirmation of species identification) above 2,300 m, which constitute altitudinal records for eastern Nepal. In the absence of previous entomological data or baseline evidence, we infer from qualitative data based on key informant interviews that these mosquito species recently established noticeable populations in the highlands of eastern Nepal.
Our results are consistent with the high-altitude Anopheles survey results of many published works. In western Nepal, the presence of An. fluviatilis and An. willmori along with their role in malaria transmission was demonstrated at high elevations $(1,310 \mathrm{~m}$ and $1,980 \mathrm{~m}$, respectively) in 1969 [43], but there has been no published evidence of malaria vectors in the highlands of eastern Nepal. In central Nepal, the malaria vectors An. fluviatilis, An. annularis, An. maculatus and other Anopheles species (An. hycranus, An. splendidus, An. subpictus and $A n$. lindesayi) were recorded up to $1,700 \mathrm{~m}$ asl in highland valleys in 1960 [16]. Pant et al. [16] also reported that An. hycranus (79\%) dominated in the highlands of central Nepal, followed in the post-monsoon season by An. fluviatilis (12\%) and An. annularis (9\%). However, in our study area in eastern Nepal we found a domination of An. annularis (16\%) followed by An. maculatus complex members (10\%) and An. fluviatilis (9\%). Our findings are consistent with data from the highland Gum Valley of Mugu district in western Nepal where An. fluviatilis and An. willmori, a member of the An. maculatus complex, had been reported to be the dominant mosquitoes and vectors of malaria [43]. Furthermore, our findings on the distribution of An. maculatus complex members are similar to those from the western Himalayas in the Gharwal region of India except for An. fluviatilis and An. annularis which were reported only below $1,000 \mathrm{~m}$ in that area [44,45]. We could not record any An. hycranus in our study, and other studies have not reported this species after 1960 in Nepal, either $[3,11,46]$. Our findings on the distribution of dengue virus and lymphatic filariasis vectors in the highlands of eastern Nepal is consistent with recent reports on their distribution in central Nepal $[47,48]$.

The findings of our study suggest that malaria and other disease vectors are already established in the highlands of Nepal posing a great health risk to mountain people who have no or only semi-immunity to malaria. In order to understand the effects of climate and other environmental change on the distribution of these malaria vectors and their potential for malaria transmission, models that integrate socio-economic, environmental and climatic variables are necessary. Nevertheless, in the absence of such studies we cannot ignore the contribution of the mobility of people, road development and an increasing access to means of transportation in accelerating distributional shifts of mosquitoes to higher altitudes. Interestingly, we exclusively found species in the highlands that are also found in the lowlands and no new species were recorded in the highlands, indicating that these species may have expanded their distributions from lowland to highland areas. However, in order to test this hypothesis molecular studies on the population genetics and historical area dynamics of these species are needed. An establishment of mosquitoes including 
known disease vectors has been reported in many studies from neighbouring countries of the Greater Himalayan region and Tibetan Plateau [49-51]. Malaria, Japanese encephalitis and lymphatic filariasis cases had previously been reported from all vector positive areas of the three districts.

The establishment of the dengue and chikungunya virus vectors $A$. aegypti and $A$. albopictus in the highlands of eastern Nepal in combination with the widespread belief of people that the use of bed nets is sufficient for preventing all mosquito-borne diseases indicates an elevated risk of chikungunya and dengue virus transmission because $A$. aegypti and $A$. albopictus are day-biting mosquitoes. These findings are consistent with those of a recent study that reported a low knowledge of dengue prevention and control in central Nepal [52]. A dengue fever outbreak was reported in the lowlands of neighbouring Jhapa district in 2012 [53] and a few cases of dengue fever from the hills of Dhankuta district in 2013 (unpublished data).

Both beneficial and adverse effects of development projects on malaria transmission have been reported in Nepal [18]. During our field work, we observed that an increasing access to water supply pipes in individual houses, the construction of ponds for fisheries, vegetable farming, road access in villages to vegetable marketing, a frequent movement of vehicles and micro-hydro power electricity gridlines in communities might have created more conducive environments for the passive and active dispersal of mosquitoes in the highlands of Nepal. We asked highland inhabitants about the prevalence of mosquitoes in their area, and these responded that mosquito problems had started in the village once the electricity line had been connected at home, and have existed 5-10 years overall. However, after a series of key informant interviews, we concluded that mosquito nuisance started 5-10 years ago following development work in the village and the problem of mosquito bites became prominent after the introduction of electricity, as electric light attracted mosquitoes in the evening. Previously, people used to light kerosene lamps and biomass fuel (wood) which acted as repellents to mosquitoes as has also been reported from India [54]. However, a review of the published literature shows no evidence that biomass smoke provides effective protection from mosquitoes and malaria [55].

The fact that malaria transmission has not been reported from higher altitudes in Nepal yet may be due to a lack of diagnostic facilities and poor recording and reporting systems as well as poor access to health services, in addition to the remoteness of the areas $[4,6,56]$. Other possible reasons include the zoophilic habits of An. fluviatilis which prefer animals over humans as prey in the highlands [16] and the use of bed nets while sleeping. During our entomological survey we also interviewed villagers about protective measures against mosquito bites, and the majority of people in households up to 2,000 m asl responded that they used bed nets throughout the year except in winter. According to the experience of community people, the density of mosquitoes starts to rise in the pre-monsoon and they disappear with the onset of winter. The perception of people on mosquitoes occurrence in the present study are consistent with results of previous studies $[36,57,58]$.

This study was conducted only in the pre- and postmonsoon seasons and therefore does not take into account the overall seasonal variations of mosquito population dynamics. Hence, further longitudinal studies in this and additional regions are recommended taking into consideration all of the seasons and a broader altitudinal coverage of Nepal. Another important point to note here is that we were unable, for logistical constraints, to survey the steep intermediate altitudinal gradient between 500 and $1,000 \mathrm{~m}$, nor areas above 2,300 m. Thus, our data cannot be extrapolated to these altitudes where totally different Anopheles species and mosquito communities might occur.

Our data revealing a present distribution of malaria vectors up to at least $1,820 \mathrm{~m}$ in eastern Nepal indicate that mountain people are at a particular risk because they lack immunity against malaria parasites. From a vector control point of view, indoor residual spraying will have little effect on the density of An. fluviatilis since these mostly hide in natural outdoor shelters. Spraying insecticides in natural outdoor shelters is impracticable because of its high cost and adverse effect on the environment. The ineffectiveness of indoor residual spraying on malaria vector density and malaria transmission has already been noted in Nepal $[4,11,46,59]$. This problem will be further aggravated by climate change which creates conducive environments for the development and breeding of mosquitoes and parasites in higher altitudes. Hence, the findings of this study will be useful for the Government of Nepal, external development partners and I/NGOs in their efforts to design and implement malaria control programs in higher altitude risk areas in order to achieve the ambitious goal of malaria elimination in Nepal by 2026 .

\section{Conclusions}

Based on the findings of our own studies in eastern Nepal, and published research evidence from central and western Nepal, malaria transmission in the higher altitudes of Nepal is possible because malaria vectors are already established in highland areas. Furthermore, infected people who are carriers or reservoirs of malaria parasites are introducing the latter to new areas due to the ever increasing movement of people to and from malaria endemic areas within the country and abroad. 
Accordingly, malaria cases have already started to be reported from the highlands of Nepal. However, they are likely grossly underreported because of the remoteness of these areas and the general belief that malaria transmission is not possible in places higher than $1,200 \mathrm{~m}$ asl in Nepal. Furthermore, the malaria control programme of the Government of Nepal is restricted to areas below $1,200 \mathrm{~m}$. Thus, we conclude that malaria vectors are already established in higher altitudes of Nepal, and vector control programmes are urgently needed to protect the health of the people living in the mountains of this country.

\section{Competing interests}

The authors declare that they have no competing interests.

\section{Authors' contributions}

MD designed the study, collected and analysed the data, and wrote the manuscript; BA critically reviewed the manuscript and UK contributed to writing and reviewing the manuscript. All authors read and approved the final manuscript.

\section{Acknowledgements}

We are grateful to the Nepal Health Research Council (NHRC) for providing ethical clearance to conduct this study. This research was financially supported by a PhD scholarship from the German Academic Exchange Service (Deutscher Akademischer Austauschdienst, DAAD) to MD and by the research funding programme "LOEWE — Landes-Offensive zur Entwicklung Wissenschaftlich-ökonomischer Exzellenz" of the Ministry of Higher Education, Research and the Arts of the State of Hesse, Germany. However, specific research funding was not received to perform this study. We are thankful to Dr. Ishan Gautam, Tribhuvan University and Mr. Promod Shrestha for their contributions in the collection and morphological identification of mosquito specimens in the field. We are also grateful to Dr. Narayan Raj Bhattarai and Mr. Ganesh Shah, BP Koirala Institute of Health Sciences, Dharan (Nepal), for their support in preserving mosquito samples in their laboratory. We thank Mr. Purushotam Gautam, Epidemiology and Diseases Control Division, Kathmandu, for information on VBD control programmes and medical entomology in Nepal. We are also grateful to Dr. Krishan Kumar Aryal and Mr. Haridatt Joshi, NHRC, for coordination and Mr. Indra Kumar Shrestha, Mr. Amir Banjara, Ms. Manjeeta Sapkota, Ms. Aradhana Kc and Ms. Lila Dhimal for their intensive support during entomological field work in Nepal. We thank Dr. Damber B. Kattel for his help to draw Figure 1. We are thankful to one anonymous reviewer for helpful comments.

\section{Author details}

${ }^{1}$ Nepal Health Research Council (NHRC), Ministry of Health and Population Complex, Ramshah Path, Kathmandu, Nepal. ${ }^{2}$ Biodiversity and Climate Research Centre (BiK-F), Senckenberg Gesellschaft für Naturforschung, Frankfurt am, Germany. ${ }^{3}$ Institute for Atmospheric and Environmental Sciences (IAU), Goethe University, Frankfurt am Main, Germany. ${ }^{4}$ Institute of Occupational Medicine, Social Medicine and Environmental Medicine, Goethe University, Frankfurt am Main, Germany.

Received: 17 October 2014 Accepted: 14 November 2014 Published online: 28 November 2014

\section{References}

1. Brydon HW, Joshi G, Pradhan S: Anopheles distribution and its relation to the malaria eradication program in Nepal. Mosq News 1961, 21(2):102-105

2. Rana KJ: History of Malaria and Malaria Control in Nepal. New Delhi: Aravail Printers and Publishers P.Ltd; 2001.

3. Darsie RF, Pradhan S: The mosquitoes of Nepal: their identification, distribution and biology. Mosquito Syst 1990, 22(2):69-130.

4. Parajuli MB, Shrestha SL, Vaidya RG, White GB: Nation-wide disappearance of Anopheles minimus Theobald, 1901, previously the principal malaria vector in Nepal. Trans Roy Soc Trop Med H 1981, 75(4):603.
5. EDCD: Report of the Internal Assessment of Malaria Control and Kala-azar Elimination Activities 2007, 2008 and 2009. Kathmandu: Epidemiology \& Disease Control Division, Department of Health Services, Ministry of Health \& Population, Government of Nepal; 2010.

6. EDCD: National Malaria Control Strategic Plan: Nepal(2007/2008-2011/012). Kathmandu: Epidemiology and Disease Control Division(EDCD), Department of Health Services, Ministry of Health and Population, Goverment of Nepal; 2007.

7. Garros C, Van Bortel W, Trung HD, Coosemans M, Manguin S: Review of the minimus complex of Anopheles, main malaria vector in southeast Asia: from taxonomic issues to vector control strategies. Trop Med Int Health 2006, 11(1):102-114.

8. Dhimal M, Ahrens B, Kuch U: Malaria control in Nepal 1963-2012: challenges on the path towards elimination. Malar J 2014, 13:241.

9. Raghavendra K, Barik T, Reddy B, P S, Dash A: Malaria vector control: from past to future. Parasitol Res 2011, 108:757-779.

10. Ramchandra Rao T: The Anophelines of India. New Delhi: Malaria Research Centre (ICMR); 1984.

11. Reisen WK, Pradhan SP, Shrestha JP, Shrestha SL, Vaidya RG, Shrestha JD: Anopheline mosquito (Diptera: Culicidae) ecology in relation to malaria transmission in the inner and outer terai of Nepal, 1987-1989. J Med Entomol 1993, 30(4):664-682.

12. Dhimal M, Ahrens $B$, Kuch U: Altitudinal shift of malaria vectors and malaria elimination in Nepal. Malar J 2014, 13(Suppl 1):26.

13. EDCD: Nepal Malaria Strategic Plan 2011-2016 (Revised Version- December 2011). Kathmandu: Epidemiology and Diseases Control Division, Department of Health Services, Ministry of Health and Population, Goverment of Nepal; 2011.

14. WHO/SEARO: Nepal Malaria Programme Review (7-16 June, 2010). New Delhi: World Health Organization Regional Office for South - East Asia; 2011

15. Banjara MR, Sirawaraporn W, Petmitr S, Imwong M, Joshi AB, Chavalitshewinkoon-Petmitr P: Characteristics and risk factors of Plasmodium falciparum malaria in Eastern and Central Nepal. Kathmandu Univ Med J 2009, 7(28):378-382.

16. Pant CP, Pradhan GD, Shrestha SL: Distribution of Anophelines in relation to Altitude in Nepal. In WHO/Mal/343. Geneva: World Health Organization; 1962:1-13.

17. White GB: Malaria receptivity stratification and projections for malaria vector control in Nepal. New Delhi: World Health Organization Regional Office for South - East Asia; 1982

18. Shrestha SL: Dynamics of malaria transmission with reference to development projects in Nepal. J Commun Dis 1985, 17(4):287-292.

19. Dahal S: Climatic determinants of malaria and kala-azar in Nepal. Reg Health Forum 2008, 12(1):33-37.

20. IPCC: Climate change 2007: The physical sciences basis. Summary for policymakers. Geneva: Intergovernmental Panel on Climate Change; 2007

21. IPCC: Climate Change 2013: The Physical Science Basis. Contribution of Working Group I to the Fifth Assessment Report of the Intergovernmental Panel on Climate Change. Cambridge, United Kingdom and New York, NY, USA: Cambridge University Press; 2013.

22. Shrestha UB, Gautam S, Bawa KS: Widespread climate change in the Himalayas and associated changes in local ecosystems. PLoS One 2012, 7(5):e36741.

23. Shrestha $A B$, Wake $C P$, Mayewski PA, Dibb JE: Maximum temperature trends in the Himalaya and its vicinity: an analysis based on temperature records from Nepal for the period 1971-94. J Climate 1999, 12(9):2775-2786

24. MOPE/HMG, UNEP: Nepal Initial National Communication to the Conference of the Parties of the United Nations Framework Convention on Climate Change. Kathmandu: Ministry of Population and Environment; 2004.

25. NCVST: Vulnerability Through the Eyes of Vulnerable: Climate Change Induced Uncertainties and Nepal's Development Predicaments. Kathmandu: Institute for Social and Environmental Transition-Nepal (ISET-N, Kathmandu) and Institute for Social and Environmental Transition (ISET, Boulder, Colorado) for Nepal Climate Vulnerability Study Team (NCVST); 2009.

26. PAN: Temporal and Spatial Variability of Climate Change over Nepal(1976-2005). Kathmandu: Practical Action Nepal; 2009.

27. Shrestha $A B$, Aryal R: Climate change in Nepal and its impact on Himalayan glaciers. Reg Environ Change 2011, 11(Suppl. 1):S65-S77. 
28. Kattel D, Yao T: Recent temperature trends at mountain stations on the southern slope of the central Himalayas. J Earth System Sci 2013, 122(1):215-227.

29. Kovats RS, Campbell-Lendrum DH, McMichael AJ, Woodward A, Cox JS: Early effects of climate change: do they include changes in vector-borne disease? Philos Trans R Soc Lond B Biol Sci 2001 356(1411):1057-1068.

30. Epstein P: The ecology of climate change and infectious diseases: comment. Ecology 2010, 91(3):925-928. discussion 928-929.

31. Confalonieri U, Menne B, Akhtar R, Ebi KL, Hauengue M, Kovats RS, Revich B, Woodward A: Human Health. In Climate Change 2007: Impacts, Adaptation and Vulnerability Contribution of Working Group II to the Fourth Assessment Report of the Intergovernmental Panel on Climate Change. 4th edition. Cambridge, UK: Cambridge University Press; 2007:391-431.

32. Liu-Helmersson J, Stenlund H, Wilder-Smith A, Rocklov J: Vectorial capacity of Aedes aegypti: effects of temperature and implications for global dengue epidemic potential. PLoS One 2014, 9(3):e89783.

33. Woodward A, Smith KR, Campbell-Lendrum D, Chadee DD, Honda Y, Liu Q, Olwoch J, Revich B, Sauerborn R: Climate change and health: on the lastest IPCC report. The Lancet 2014, 383(April 5):1185-1189.

34. Siraj AS, Santos-Vega M, Bouma MJ, Yadeta D, Ruiz Carrascal D, Pascual M: Altitudinal changes in malaria incidence in highlands of Ethiopia and Colombia. Science 2014, 343(6175):1154-1158.

35. Caminade C, Kovats S, Rocklov J, Tompkins AM, Morse AP, Colon-Gonzalez FJ, Stenlund H, Martens P, Lloyd SJ: Impact of climate change on global malaria distribution. Proc Natl Acad Sci U S A 2014, 111(9):3286-3291.

36. MoE: National Adaptation Program of Action to Climate Change (NAPA). Kathmandu: Goverment of Nepal, Ministry of Envrionment; 2010.

37. WHO: Manual on practical entomology in malaria part II: methods and techniques. Geneva: World Health Organization; 1975.

38. Nagpal BN, Shrivastav A, Saxena R, Ansari MA, Dash AP, Das SC: Pictorial identification keys for indian mosquitoes. Madhuban: Delhi-110 092: Malaria Research Centre (ICMR); 2005:1-40.

39. Rueda LM: Pictorial keys for identification of mosquitoes (Diptera: Culicidae) associated with dengue virus transmission. In Zootaxa (589). Auckland, Newzealand: Magnolia Press; 2004

40. Animut A, Gebre-Michael T, Balkew M, Lindtjorn B: Abundance and dynamics of anopheline larvae in a highland malarious area of south-central Ethiopia. Parasite \& vectors 2012, 5:117.

41. R Development Core Team: R: A Language and Environment for Statistical Computing 2.15.2. Vienna, Austria: R Foundation for Statistical Computing; 2012.

42. Venables WN, Ripley BD: Modern Applied Statistics With S. 4th edition. New York: Springer; 2002.

43. Pradhan JM, Shrestha SL, Vaidya RG: Malaria transmissionin high mountain valleys of west Nepal including first record of Anopheles maculatus willmori (James) as a third vector of malaria. J Nep Med Ass 1970, 8:89-97.

44. Devi NP, Jauhari RK: Altitudinal distribution of mosquitoes in mountainous area of Garhwal region: Part-I. J Vector Borne Dis 2004, 41(1-2):17-26.

45. Devi N, Jauhari RK: Mosquito species associated within some western Himalayas phytogeographic zones in the Gharwal region of India. J Insect Sci 2007, 7(32):1-10.

46. Shrestha SL, Pradhan S, Shrestha JPB, Shrestha JD, Rajbhamdari Y, Shrestha GL, Swar TB, Nushin MK, Reisen WK: Observations on anopheline and malaria ecology in the Far Western Region of Nepal, 1986. Bull Soc Vector Ecol 1988, 13(2):332-342.

47. Dhimal M, Gautam I, Kress A, Muller R, Kuch U: Spatio-temporal distribution of dengue and lymphatic filariasis vectors along an altitudinal transect in central Nepal. PLoS Negl Trop Dis 2014, 8(7):e3035.

48. Byanju R, Gautam I, Aryal M, Aradhana K, Shrestha HN, Dhimal M: Adult density of Culex quinquefasciatus Say, filarial vector in Thapa Gaun, Jhaukhel and Lama Tole, Nagarkot VDC, Bhaktapur District. Nepal J SCi Tech 2013, 14(1):185-194.

49. Aditya G, Pramanik MK, Saha GK: Larval habitats and species composition of mosquitoes in Darjeeling Himalayas. India J Vector Borne Dis 2006, 43(1):7-15.

50. Liu Q, Liu X, Cirendunzhu, Woodward A, Pengcuociren, Bai L, Baimaciwang, Sang S, Dazhen, Wan F, Zhou L, Guo Y, Wu H, Li G, Lu L, Wang J, Dawa,
Chu C, Xiraoruodeng: Mosquitoes established in Lhasa city, Tibet, China. Parasite \& vectors 2013, 6:224

51. Narain JP: Climate change and its potential impact on vector-borne diseases. In Health in South - East Asia: A SEARO Newsletter. New Delhi: WHO SEARO; 2008:13-15.

52. Dhimal M, Aryal KK, Dhimal ML, Gautam I, Singh SP, Bhusal CL, Kuch U: Knowledge, attitude and practice regarding dengue fever among the healthy population of highland and lowland communities in central Nepal. PLoS One 2014, 9(7):e102028.

53. DoHS: Annual Report 2069/2070(2012/2013). Kathmandu: Department of Health Services, Minsitry of Health and Population, Goverment of Nepal; 2014

54. Babu BV, Mishra S, Mishra S, Swain BK: Personal-protection measures against mosquitoes: a study of practices and costs in a district, in the Indian state of Orissa, where malaria and lymphatic filariasis are co-endemic. Ann Trop Med Parasitol 2007, 101(7):601-609.

55. Biran A, Smith L, Lines J, Ensink J, Cameron M: Smoke and malaria: are interventions to reduce exposure to indoor air pollution likely to increase exposure to mosquitoes? Trans R Soc Trop Med Hyg 2007, 101(11):1065-1071.

56. DoHS: Annual Report 2067/68 (2010/2011) Kathmandu: Department of Health Services. Goverment of Nepal: Ministry of Health and Population; 2012.

57. Chaudhary P, Bawa KS: Local perceptions of climate change validated by scientific evidence in the Himalayas. Biol Letters 2011, 7(5):767-770.

58. Dhimal M, Bhusal CL: Impacts of climate change on human health and adaptation strategies for Nepal. J Nepal Health Res Counc 2009, 7(15):140-141

59. Dhimal M, O'Hara RB, Karki RC, Thakur GD, Kuch U, Ahrens B: Spatiotemporal distribution of malaria and its association with climatic factors and vector control interventions in two high-risk districts of Nepal. Malar J 2014, 13:457.

doi:10.1186/s13071-014-0540-4

Cite this article as: Dhimal et al:: Species composition, seasonal occurrence, habitat preference and altitudinal distribution of malaria and other disease vectors in eastern Nepal. Parasites \& Vectors 2014 7:540.

\section{Submit your next manuscript to BioMed Central and take full advantage of:}

- Convenient online submission

- Thorough peer review

- No space constraints or color figure charges

- Immediate publication on acceptance

- Inclusion in PubMed, CAS, Scopus and Google Scholar

- Research which is freely available for redistribution

Submit your manuscript at www.biomedcentral.com/submit
C Biomed Central 